\title{
Localization and Potential Role of Matrix Metalloproteinase-1 and Tissue Inhibitors of Metalloproteinase-1 and -2 in Different Phases of Bronchopulmonary Dysplasia
}

\author{
WILLEM A. DIK, RONALD R. DE KRIJGER, LAMBERT BONEKAMP, BRIGITTA A.E. NABER, \\ LUC J.I. ZIMMERMANN, AND MARJAN A. VERSNEL \\ Departments of Immunology [W.A.D., L.B., B.A.E.N., M.A.V.], Pathology [R.R.d.K.], and Pediatrics \\ [B.A.E.N., L.J.I.Z.], Sophia Children's Hospital, Division of Neonatology, Erasmus University Rotterdam \\ and University Hospital Rotterdam-Dijkzigt
}

\begin{abstract}
ABS
Bronchopulmonary dysplasia (BPD) can evolve in prematurely
born infants who require mechanical ventilation because of hyaline
membrane disease (HMD). The development of BPD can be di-
vided in an acute, a regenerative, a transitional, and a chronic phase.
During these different phases, extensive remodeling of the lung
parenchyma with re-epithelialization of the alveoli and formation of
fibrosis occurs. Matrix metalloproteinase-1 (MMP-1) is an enzyme
that is involved in re-epithelialization processes, and dysregulation
of MMP-1 activity contributes to fibrosis. Localization of MMP-1
and its inhibitors, tissue inhibitor of metalloproteinase (TIMP)-1 and
TIMP-2, were investigated in lung tissue obtained from infants who
died during different phases of BPD development. In all studied
cases (n = 50) type-II pneumocytes were found to be immunore-
active for MMP-1, TIMP-1, and TIMP-2. During the acute and
regenerative phase of BPD, type-II pneumocytes re-epithelialize the
injured alveoli. This may suggest that MMP-1 and its inhibitors,
expressed by type-II pneumocytes, play a role in the re-
epithelialization process after acute lung injury. Although MMP-1
staining intensity remained constant in type-II pneumocytes during
\end{abstract}
Respiratory distress syndrome develops within minutes after birth in premature infants and is associated with surfactant deficiency of the immature lung $(1,2)$. Pathologically, it is called hyaline membrane disease (HMD), with the formation of hyaline membranes in the terminal airways being one of the most striking pathologic features (3).

Hyaline membrane formation is caused by necrosis and desquamation of epithelial cells lining the alveolar basement membrane and the occurrence of pulmonary edema (3-5). To sustain life, infants are treated with mechanical ventilation and

Received November 29, 2000; accepted June 15, 2001.

Correspondence and reprint requests: W.A. Dik, Department of Immunology, Erasmus University Rotterdam, P.O. Box 1738, 3000 DR Rotterdam, The Netherlands; e-mail: dik@immu.fgg.eur.nl.

Supported by The Sophia Foundation for Medical Research.
BPD development, TIMP-1 increased during the chronic fibrotic phase. This relative elevation of TIMP-1 compared with MMP-1 is indicative for reduced collagenolytic activity by type-II pneumocytes in chronic BPD and may contribute to fibrosis. Fibrotic foci in chronic BPD contained fibroblasts immunoreactive for MMP-1 and TIMP-1 and -2. This may indicate that decreased collagen turnover by fibroblasts contributes to fibrosis in BPD development. (Pediatr Res 50: 761-766, 2001)
Abbreviations
BPD, Bronchopulmonary dysplasia
HMD, Hyaline membrane disease
MMP-1, Matrix metalloproteinase-1
MMPs, Matrix metalloproteinases
TIMP-1, Tissue inhibitor of metalloproteinase-1
TIMP-2, Tissue inhibitor of metalloproteinase-2
TIMPs, Tissue inhibitors of metalloproteinases
TGF- $\boldsymbol{\beta}$, Transforming growth factor- $\beta$

supplemental oxygen, which are both risk factors for the progression of HMD toward bronchopulmonary dysplasia (BPD) (6).

BPD, also called chronic lung disease of prematurity, can be regarded as the end stage of HMD treatment and is associated with mortality and long term pulmonary morbidity $(6,7)$. The development from HMD to BPD is characterized by extensive tissue remodeling and can be divided into four phases based on days after birth: acute $(2-4 \mathrm{~d})$, regenerative $(4-8 \mathrm{~d})$, transitional ( $8-16 \mathrm{~d})$, and chronic (>16 d) (8). A main feature of the acute and regenerative phase is re-epithelialization of the denuded alveoli. The transitional and chronic phases are characterized by alveoli primarily lined with type-II pneumocytes and the occurrence of fibrotic areas and increased numbers of fibroblasts $(3,9,10)$. 
During the re-epithelialization process, hyaline membranes form a matrix on which type-II pneumocytes adhere and regenerate. This process incorporates hyaline membranes into the alveolar septal wall. Incorporated hyaline membranes, which contain fibronectin, are associated with areas of fibrosis during BPD development $(9,11,12)$.

Matrix metalloproteinases (MMPs) are a group of enzymes capable of degrading extracellular matrix proteins. MMPs play a critical role in normal physiologic processes like development, tissue remodeling, inflammation, angiogenesis, wound healing, and cell migration (13). The expression of MMPs is regulated at the transcriptional level by cytokines, growth factors, and extracellular matrix components $(14,15,16)$. MMPs are secreted as latent pro-enzymes and require proteolytic cleavage for activation. MMP-1 is capable of degrading the fibrillar collagens-type-I, -II, -III, collagen type-X, gelatin, and proteoglycans (17).

In vitro studies have shown that type-II pneumocytes, the cells that initiate alveolar re-epithelialization, are able to produce MMP-1 and thereby promote their own migration (18, 19). Therefore, MMP-1 may play a role in the re-epithelialization process of the alveoli during the acute and regenerative phase of BPD development, comparable with the role for MMP-1 in re-epithelialization of the skin after injury $(20,21)$. Tissue inhibitors of matrix metalloproteinase (TIMP)-1 and TIMP-2 inhibit active MMP-1(22). It was shown that disturbed MMP-1, TIMP-1, and TIMP-2 regulation plays an important role in pathologic processes like fibrotic liver disease and pulmonary fibrosis (23-27).

Therefore, we expect MMP-1, TIMP-1, and TIMP-2 to contribute to the remodeling process of lung tissue when HMD progresses toward BPD. This urged us to study the immunohistochemical localization of MMP-1, TIMP-1, and TIMP-2 in lung tissue obtained from infants who died during different phases of BPD development.

\section{METHODS}

Patients. Autopsy lung specimens were selected in the files of the department of Pathology from the years 1988-1998, based on premature infants who where histologically and clinically diagnosed as HMD/BPD. HMD was clinically defined as respiratory distress for which ventilation was necessary and a pulmonary $\mathrm{x}$-ray pattern compatible with HMD (28). All patients were still on oxygen when they died. Therefore, per definition all patients that died after $28 \mathrm{~d}$ fulfilled the clinical BPD definition according to Bancalari (29). Staging of the histologic samples was performed according to Rosan (8). In total, 50 prematurely born infants with pathologic findings of BPD or HMD, who died of respiratory insufficiency, were selected (all patients $(n=12)$ before 1990 died because of respiratory insufficiency alone; after 1990, 26 infants died because of respiratory insufficiency alone; in the other 12 patients respiratory insufficiency coexisted with heart failure or intraventricular hemorrhage). As controls, specimens were taken from three term infants who died of nonpulmonary causes and lived for 9,14, and $30 \mathrm{~d}$, respectively.
Immunohistochemistry. Paraffin embedded lung tissue was cut into four $\mu \mathrm{m}$ sections, incubated overnight at $37^{\circ} \mathrm{C}$, deparaffinized, and rehydrated. Afterward, the slides were washed in phosphate-buffered saline (PBS, $\mathrm{pH}$ 7.8) for $5 \mathrm{~min}$ and incubated with $0.1 \%$ pepsin A (Sigma Chemical Co. Chemical Company, St. Louis, MO, U.S.A.) in $0.01 \mathrm{M} \mathrm{HCl}$ for $30 \mathrm{~min}$ at $37^{\circ} \mathrm{C}$ for antigen retrieval. The slides were subsequently rinsed in PBS of $4^{\circ} \mathrm{C}$ for $5 \mathrm{~min}$, followed by blocking of endogenous biotin activity with an avidin/biotin blocking kit (Vector Laboratories, Burlingame, CA, U.S.A.). Afterward, the slides were rinsed for $15 \mathrm{~min}$ in PBS followed by $10 \mathrm{~min}$ in PBS containing $0.2 \%$ Tween 20 . The slides were then incubated for $5 \mathrm{~min}$ with PBS containing $1 \%$ bovine serum albumin (BSA) followed by a $1 \mathrm{~h}$ incubation with PBS containing 1\% BSA and $10 \%$ normal human serum (NHS). This was followed by rinsing the slides for two times $5 \mathrm{~min}$ in washbuffer (PBS containing $0.1 \%$ BSA and $0.2 \%$ Tween 20 ). Subsequently, the slides were incubated for $1 \mathrm{~h}$ with $10 \%$ normal goat serum diluted in PBS containing 1\% BSA for MMP-1 and TIMP-2 staining or $10 \%$ normal rabbit serum diluted in PBS containing $1 \%$ BSA for TIMP-1 staining. Then the slides were incubated with the primary antibodies diluted in PBS containing $1 \%$ BSA and $10 \%$ normal goat or rabbit serum (mouse anti-human MMP-1; 1:200 dilution; mouse anti-human TIMP-2; 1:20 dilution, ICN Biomedicals, Aurora, $\mathrm{OH}$, and goat anti-human TIMP-1; 1:40 dilution, Santa Cruz Biotechnology, Santa Cruz, CA, U.S.A.) overnight at $4^{\circ} \mathrm{C}$. Afterward, the slides were rinsed for $5 \mathrm{~min}$ in washbuffer, which was followed by two wash steps of $15 \mathrm{~min}$. Subsequently, the slides were incubated for 30 min with biotin-labeled goat-anti-mouse (Biogenex, San Ramon, CA, U.S.A.) or rabbit-anti-goat (DAKO, Glostrup, Denmark) at a 1:50 and 1:20 dilution in PBS containing 1\% BSA and $10 \%$ NHS, respectively. Then the slides were rinsed for $5 \mathrm{~min}$ followed by two times $15 \mathrm{~min}$ in washbuffer. This was followed by incubating the slides for 30 min with a 1:50 dilution of Streptavidin-alkaline-phosphatase (Biogenex) in PBS containing 1\% BSA. Afterward, the slides were rinsed once 5 and once $15 \mathrm{~min}$ with washbuffer and rinsed for $5 \mathrm{~min}$ in $0.2 \mathrm{M}$ Tris- $\mathrm{HCl}(\mathrm{pH}$ 8.0). Subsequently, the slides were incubated for 30 min with New Fuchsin substrate (Chroma, Stuttgart, Germany). Finally the slides were rinsed with PBS, counterstained with Mayers hematoxylin (Merck, Darmstadt, Germany) and mounted in Kaiser's glycerol (Merck). Control staining was performed by substitution of the primary antibody with PBS. R.R.d.K. and L.B. performed the evaluation of the stained sections in a blinded fashion. The cells and structures examined in this study were the alveolar macrophage, the alveolar type-II pneumocyte, the alveolar basement membrane, and fibroblasts in fibrotic foci. The staining intensity of the sections was scored in a semiquantitative manner according to the following method: no staining $=0$, diffuse very faint staining $=1$, diffuse faint staining $=2$, diffuse moderate staining $=3$, and diffuse strong staining $=4$.

Statistical analysis. Data on staining intensity are presented as median and percentiles (10\% to $90 \%)$ for the different phases of BPD development. For evaluation of differences in staining intensity between different phases of BPD develop- 
ment the Mann-Whitney $\mathrm{U}$ test was used. A $p$ value less than 0.05 was considered significant.

\section{RESULTS}

Patients. BPD is considered as a gradually developing sequel of the original diagnosed HMD (acute phase of BPD development) and its treatment (8). Therefore, we applied the time phases for BPD development, according to Rosan, to the patient group (8). Twenty seven patients were included in the acute phase $(0-4 \mathrm{~d})$, seven in the regenerative phase $(5-8 \mathrm{~d})$, nine in the transitional phase $(9-16 \mathrm{~d})$, and seven in the chronic phase $(>16 \mathrm{~d})$. The control patients were regarded as one group, independent of their age at death. Clinical data of the different phases of BPD development and of control patients are shown in Table 1.

MMP-1, TIMP-1, and TIMP-2 expression. An overview of the immunohistochemical detection for MMP-1, TIMP-1, and TIMP-2, presented as positive or negative immunoreactivity, is shown in Table 2.

Control lung tissue. Control lung tissue revealed scattered MMP-1, TIMP-1, and -2 positive type-II pneumocytes and alveolar macrophages. TIMP-1 reactivity was also detected in the alveolar basement membrane (Fig. 1).

Acute phase (0-4 d). Lung tissue of the patients who died early in the acute phase $(<1 \mathrm{~d})$ was characterized by extensive loss of alveolar epithelial cells and the formation of hyaline membranes. Because of extensive loss of alveolar epithelial cells, virtually no reactivity with MMP-1, TIMP-1, and TIMP-2 was observed in the alveolar epithelium. However, if cuboidal type-II-like pneumocytes were present, they stained positive for MMP-1, TIMP-1, and TIMP-2. During progression toward day 4 in the acute phase, the lung tissue showed hyaline membranes covering cells positive for MMP-1, TIMP-1, and TIMP-2. Furthermore, regenerating epithelial cells positive for MMP-1, TIMP-1, and TIMP-2 epithelialized the hyaline membranes, incorporating them into the alveolar septum. In most cases a clear positive staining for TIMP-1 was localized to the alveolar basement membrane, which was observed underneath epithelial cells as well as underneath hyaline membranes. Alveolar macrophages showed no difference in immunostaining for MMP-1, TIMP-1, and TIMP-2 compared with control lung tissue.

Regenerative phase (5-8 d). During the regenerative phase hyaline membranes were still present in the tissue and clearly became incorporated into the alveolar wall. The incorporated membranes were covered by cuboidal type-II-like pneumocytes that stained positive for MMP-1, TIMP-1, and TIMP-2
(Fig. 2). In most cases TIMP-1 positivity was also observed in parts of the alveolar basement membrane, similar to the situation in the acute phase. Alveolar macrophages present in this phase showed a similar positivity for MMP-1, TIMP-1, and TIMP-2 as detected in the control lung tissue.

Transitional phase (9-16 d). During the transitional phase less hyaline membranes were present. If present, they were covered with cuboidal type-II-like pneumocytes, which stained positive for MMP-1, TIMP-1, and TIMP-2. Furthermore, the alveolar surface appeared to be covered exclusively with typeII-like pneumocytes, which were MMP-1, TIMP-1, and TIMP-2 positive. Alveolar macrophages, which were more frequently present than in the previous stages, also stained positive for MMP-1, TIMP-1, and TIMP-2 (Fig. 3). TIMP-1 immunoreactivity in the alveolar basement membrane differed from barely detectable in some patients to prominent in others.

Chronic phase (>16 d). During the chronic phase hyaline membranes were virtually absent. The alveoli appeared to be covered exclusively with type-II-like pneumocytes immunoreactive for MMP-1, TIMP-1, and TIMP-2. In some cases the alveoli appeared emphysematous. Alveolar macrophages also revealed positive staining for MMP-1, TIMP-1, and TIMP-2. During this chronic phase, interstitial fibrosis was a prominent feature. Fibrotic areas contained fibroblasts positive for MMP-1, TIMP-1, and TIMP-2 (Fig. 4). Immunostaining for TIMP-1 in the alveolar basement membrane varied from barely detectable in some patients to prominent in others. If the primary antibody was omitted, no immunoreactivity was detected (Fig. 4D).

Semiquantitative analysis of immunoreactivity during BPD development. Semiquantitative analysis of immunoreactivity revealed no difference in MMP-1 and TIMP-2 staining intensity between the four phases of BPD development. However, TIMP-1 showed a marked increase in staining intensity in the type-II pneumocytes that formed the alveolar lining in the chronic phase of BPD compared with the earlier phases (Fig. $5)$.

\section{DISCUSSION}

In the present study we investigated the expression pattern of MMP-1 and its inhibitors, TIMP-1 and TIMP-2, in the lung during the development of BPD. MMP-1 was co-localized with TIMP-1 and TIMP-2 in type-II pneumocytes and alveolar macrophages. TIMP-1 also localized to the alveolar basement membrane.

The expression of MMP-1, TIMP-1, and TIMP-2 by type-II pneumocytes and alveolar macrophages in the healthy lung

Table 1. Clinical data of BPD and control patients

\begin{tabular}{|c|c|c|c|c|c|}
\hline BPD stage & $\begin{array}{l}\text { Gestational age } \\
\text { (weeks)* }\end{array}$ & $\begin{array}{l}\text { Age at death } \\
\text { (days)* }\end{array}$ & $\begin{array}{l}\text { Weight at death } \\
\text { (kilograms)* }\end{array}$ & Male:Female & $\begin{array}{c}\text { Number of } \\
\text { patients }\end{array}$ \\
\hline Acute phase & $28.9(24.9-36)$ & $2(0.08-4)$ & $1.1(0.58-3.0)$ & $2: 1$ & 27 \\
\hline Regenerative phase & $25.6(25-30)$ & $6(5-8)$ & $1.1(0.56-1.4)$ & $4: 3$ & 7 \\
\hline Chronic phase & $28(25-31.7)$ & $35(21-304)$ & $1.1(0.85-5.0)$ & $6: 1$ & 7 \\
\hline Controls & term & $14(9-30)$ & $2.9(2.9-3.7)$ & $1: 2$ & 3 \\
\hline
\end{tabular}

* Median value (range). 
Table 2. Localization of MMP-1, TIMP-1, and TIMP-2 during different phases of BPD and in control tissue

\begin{tabular}{|c|c|c|c|c|c|c|c|c|c|c|c|c|c|c|c|}
\hline & \multicolumn{3}{|c|}{ Acute phase } & \multicolumn{3}{|c|}{ Regenerative phase } & \multicolumn{3}{|c|}{ Transitional phase } & \multicolumn{3}{|c|}{ Chronic phase } & \multicolumn{3}{|c|}{ Control tissue } \\
\hline & MMP-1 & TIMP-1 & TIMP-2 & MMP-1 & TIMP-1 & TIMP-2 & MMP-1 & TIMP-1 & TIMP-2 & MMP-1 & TIMP-1 & TIMP-2 & MMP-1 & TIMP-1 & TIMP-2 \\
\hline Type-II pneumocytes & + & + & + & + & + & + & + & + & + & + & + & + & + & + & + \\
\hline Alveolar macrophages & + & + & + & + & + & + & + & + & + & + & + & + & + & + & + \\
\hline $\begin{array}{l}\text { Fibroblasts in fibrotic } \\
\text { area }\end{array}$ & - & - & - & - & - & - & - & - & - & + & + & + & - & - & - \\
\hline
\end{tabular}

$+=$ immunoreactivity.

$-=$ no immunoreactivity.

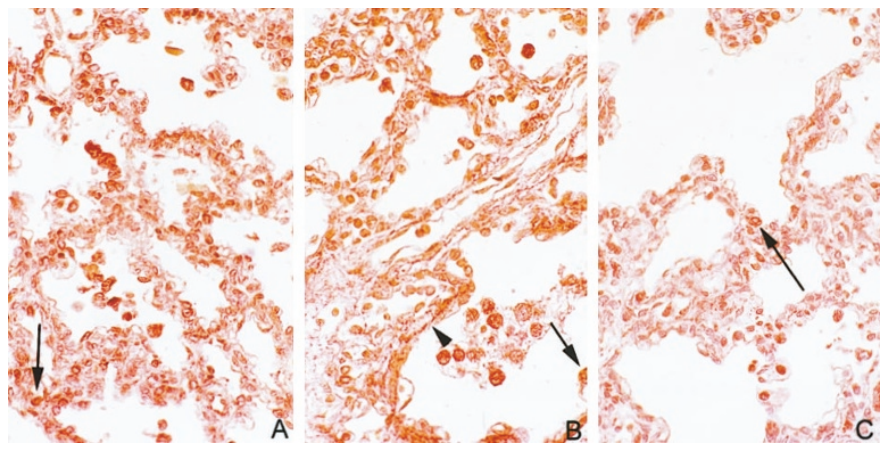

Figure 1. Immunohistochemical staining of control lung tissue. MMP-1 $(A)$, TIMP-1 $(B)$, and TIMP-2 $(C)$ immunoreactivity is detected in type-II pneumocytes (arrow) and alveolar macrophages. TIMP-1 $(B)$ immunoreactivity is detected in the alveolar basement membrane (arrowhead).

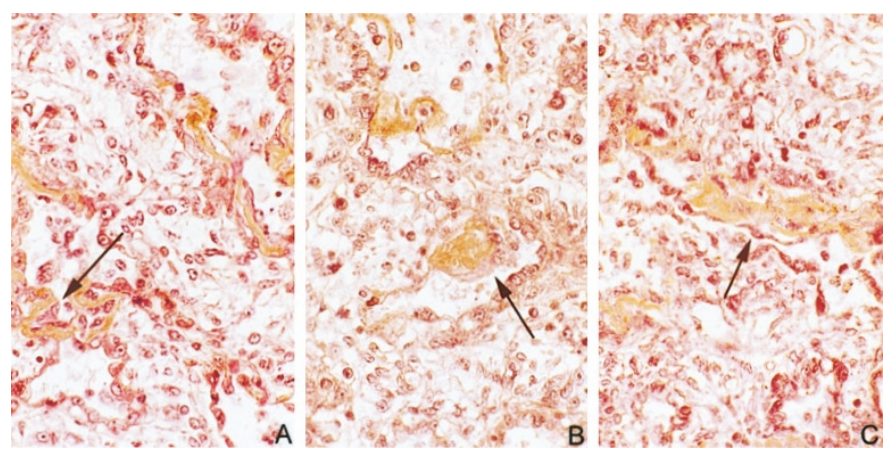

Figure 2. Immunohistochemical staining of lung tissue in the regenerative phase of BPD development. MMP-1 $(A)$, TIMP-1 $(B)$, and TIMP-2 $(C)$ immunoreactivity is detected in type-II pneumocytes re-epithelializing the alveoli and incorporating hyaline membranes (arrow).

may play a role in the extracellular matrix turnover, which is a constant feature in lung tissue $(30,31)$. The presence of TIMP-1 in the basement membrane may prevent this structure from degradation by MMPs or may provide a barrier function for active MMPs to reach the lung interstitium to control extracellular matrix turnover.

After lung injury and during lung development, the type-II pneumocyte is the progenitor cell for the formation of a functional alveolar epithelium $(32,33)$. Migration of type-II pneumocytes over hyaline membrane-like matrices has been suggested to play an important role during re-epithelialization after acute injury. The $\alpha 2 \beta 1$-integrin on type-II pneumocytes mediates the migration on collagen type-I, a substrate for and inducer of MMP-1 production $(17,34,35)$. Recently, an in vitro study described that MMP-1 decreased the type-II pneu-
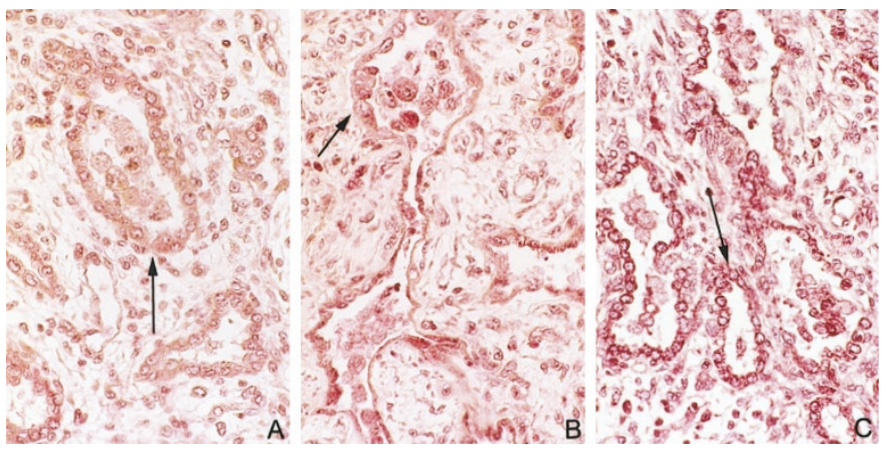

Figure 3. Immunohistochemical staining of lung tissue in the transitional phase of BPD development. MMP-1 $(A)$, TIMP-1 $(B)$, and TIMP-2 $(C)$ immunoreactivity is detected in type-II pneumocytes covering the entire alveolar surface (arrow) and in alveolar macrophages.
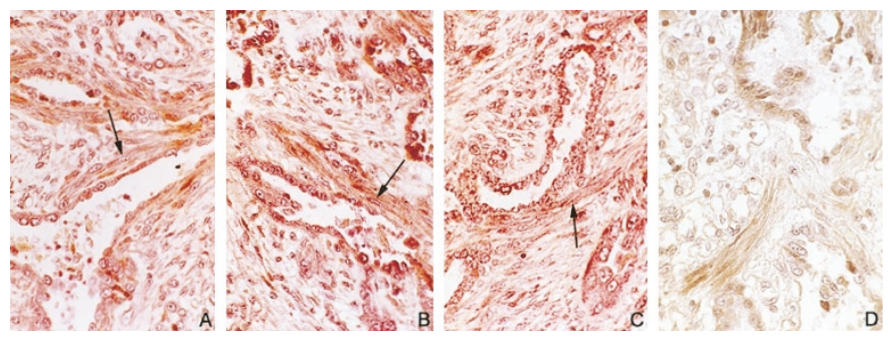

Figure 4. Immunohistochemical staining of lung tissue in the chronic phase of BPD development. MMP-1 $(A)$, TIMP-1 $(B)$, and TIMP-2 $(C)$ immunoreactivity is detected in fibroblasts present in fibrotic foci (arrow) and in type-II pneumocytes covering the entire alveolar surface. 4D is negative control.

mocyte cytoskeleton stiffness, the adhesion to collagen type-I, and increased cell migration across collagen type-I (19). Regarding these observations and the expression of MMP-1, TIMP-1, and TIMP-2 by type-II pneumocytes on hyaline membranes in the acute and regenerative phases of BPD development, we speculate that MMP-1 is involved in reepithelialization of the alveolar surface during the acute and regenerative phase of BPD development. The colocalization of TIMP-1 and TIMP-2 with MMP-1 indicates that these inhibitors regulate the activity of MMP-1 during this process. Analysis of lung homogenates could reveal information about in vivo MMP-1 activity and the ratio of MMP-1/TIMPs. Furthermore, the relative amounts of active and latent MMP-1 could be determined, because both forms are recognized with the antibody used in this study.

The saccular stage of fetal lung development is characterized by alveoli mainly lined by type-II pneumocytes. During this stage, thinning of the interstitial matrix between alveoli occurs. 


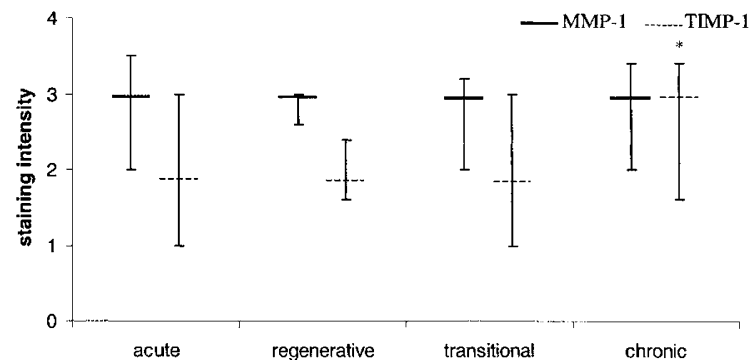

Figure 5. Semiquantitative analysis of MMP-1 and TIMP-1 in type-II pneumocytes during different developmental phases of BPD. Results for staining intensity are expressed as median and percentiles (10\% to $90 \%)$ per group of patients in the four different phases of BPD development. Semiquantitative scoring was assessed as follows: no staining $=0$, diffuse very faint staining $=1$, diffuse faint staining $=2$, diffuse moderate staining $=3$, and diffuse strong staining $=4 .{ }^{*} p<0.05$ compared with acute phase.

It has been suggested that epithelial cells over-expressing MMP-1 relative to TIMP-1 contribute to the net degradation of interstitial collagens during this process (36-39). During the transitional and chronic phase of BPD we observed virtually no hyaline membranes and the alveoli were almost exclusively lined by hyperplastic MMP-1, TIMP-1, and -2 positive type-II pneumocytes. Furthermore, fibrotic areas in the alveolar septa were clearly present in chronic BPD. Fibrotic areas are characterized by increased numbers of fibroblasts and accumulation of fibrillar collagens, mainly collagens type-I and type-III (3, 40-43). MMP-1 exerts collagenolytic activity against fibrillar collagen. We observed increased staining intensity for TIMP-1 in type-II pneumocytes in the chronic phase of BPD compared with the earlier phases, whereas no difference in MMP-1 staining intensity in type-II pneumocytes was observed. This might result in an increased TIMP-1/MMP-1 ratio leading to decreased collagenolytic activity by type-II pneumocytes, thereby favoring interstitial collagen accumulation (fibrosis) as is observed in chronic BPD and is opposed to normal lung development.

Fibroblasts are the key cells in a fibrotic response, contributing to collagen deposition via increased proliferation, increased collagen synthesis, or decreased collagen breakdown (44). Lung tissue from patients with idiopathic pulmonary fibrosis has been shown to contain decreased collagenolytic activity and lung fibroblasts from these patients show an increased ratio of TIMP/MMP-1 compared with normal lung fibroblasts $(25,45)$. It has been suggested that co-expression of MMP-1 and TIMP-2 in fibroblasts in fibrotic foci from patients with idiopathic pulmonary fibrosis contributes to progressive collagen deposition caused by decreased collagenolytic activity. On the other hand, a predominance of MMP-1 in fibroblasts in fibrotic foci in bronchiolitis obliterans organizing pneumonia could explain the reversibility of fibrotic changes in that disease (27). Our study revealed that during the chronic phase of BPD, fibroblasts in fibrotic areas were associated with the expression of MMP-1, TIMP-1, and TIMP-2. Inhibition of collagen degradation by decreasing the production of MMP-1 and increasing the production of TIMPs by fibroblasts has been reported for transforming growth factor- $\beta$ (TGF- $\beta 1$ ) (46). Interestingly, intense immunoreactivity for TGF- $\beta 1$ has been shown in alveolar macrophages and fibroblasts in lung tissue during the regenerative and transitional stages of BPD (37). Therefore, during BPD development TGF- $\beta 1$ could increase the TIMP/MMP-1 ratio in fibroblasts. This would lead to a decreased collagenolytic activity and favors net deposition of collagen by fibroblasts, thereby contributing to fibrosis of the lung tissue.

In the present study we observed MMP-1 expression in type-II epithelial cells re-epithelializing the injured alveoli. From the literature there is abundant evidence that MMP-1 is involved in re-epithelialization after injury. Therefore, this may suggest a role for MMP-1 expressed by type-II pneumocytes in the re-epithelialization process after acute injury during the acute and regenerative phase of BPD development. The increase in intensity of TIMP-1 relative to MMP-1 in type-II pneumocytes during the chronic phase of BPD might result in decreased interstitial collagen breakdown, thereby contributing to fibrosis as observed in chronic BPD. Furthermore, fibroblasts co-expressing MMP-1 and TIMPs in fibrotic areas may contribute to fibrosis in chronic BPD via a decreased collagenolytic activity, due to an increased TIMP/MMP-1 ratio.

Acknowledgments. We gratefully acknowledge Prof. Dr. R. Benner and Dr. V.H.J. van der Velden for critical reading of the manuscript.

\section{REFERENCES}

1. Avery ME, Mead J 1959 Surface properties in relation to atelectasis and hyaline membrane disease. Am J Dis Child 97:517-523

2. Reynolds EO, Roberton NR, Wigglesworth JS 1968 Hyaline membrane disease, respiratory distress, and surfactant deficiency. Pediatrics 42:758-768

3. Anderson WR 1990 Bronchopulmonary dysplasia: a correlative study by light, scanning, and transmission electron microscopy. Ultrastruct Pathol 14:221-232

4. Gandy G, Jacobson W, Gairdner D 1970 Hyaline membrane disease. I. Cellular changes. Arch Dis Child 45:289-310

5. de la Monte SM, Hutchins GM, Moore GW 1986 Respiratory epithelial cell necrosis is the earliest lesion of hyaline membrane disease of the newborn. Am J Pathol 123:155-160

6. O'Brodovich HM, Mellins RB 1985 Bronchopulmonary dysplasia. Unresolved neonatal acute lung injury. Am Rev Respir Dis 132:694-709

7. Northway Jr WH 1990 Bronchopulmonary dysplasia: then and now. Arch Dis Child 65:1076-1081

8. Rosan RC 1975 Hyaline membrane disease and a related spectrum of neonatal pneumopathies. Perspect Pediatr Pathol 2:15-60

9. Anderson WR, Engel RR 1983 Cardiopulmonary sequelae of reparative stages of bronchopulmonary dysplasia. Arch Pathol Lab Med 107:603-608

10. Margraf LR, Paciga JE, Balis JU 1990 Surfactant-associated glycoproteins accumulate in alveolar cells and secretions during reparative stage of hyaline membrane disease. Hum Pathol 21:392-396

11. Fukuda Y, Ferrans VJ, Schoenberger CI, Rennard SI, Crystal RG 1985 Patterns of pulmonary structural remodeling after experimental paraquat toxicity. The morphogenesis of intraalveolar fibrosis. Am J Pathol 118:452-475

12. Sinkin RA, Roberts M, LoMonaco MB, Sanders RJ, Metlay LA 1998 Fibronectin expression in bronchopulmonary dysplasia. Pediatr Dev Pathol 1:494-502

13. O'Connor CM, FitzGerald MX 1994 Matrix metalloproteases and lung disease. Thorax 49:602-609

14. Mauviel A 1993 Cytokine regulation of metalloproteinase gene expression. J Cell Biochem 53:288-295

15. Shapiro SD, Senior RM 1999 Matrix metalloproteinases. Matrix degradation and more. Am J Respir Cell Mol Biol 20:1100-1102

16. Sudbeck BD, Pilcher BK, Welgus HG, Parks WC 1997 Induction and repression of collagenase- 1 by keratinocytes is controlled by distinct components of different extracellular matrix compartments. J Biol Chem 272:22103-22110

17. Murphy G, Docherty AJ 1992 The matrix metalloproteinases and their inhibitors. Am J Respir Cell Mol Biol 7:120-125

18. Pardo A, Ridge K, Uhal B, Sznajder JI, Selman M 1997 Lung alveolar epithelial cells synthesize interstitial collagenase and gelatinases A and B in vitro. Int J Biochem Cell Biol 29:901-910

19. Planus E, Galiacy S, Matthay M, Laurent V, Gavrilovic J, Murphy G, Clerici C, Isabey D, Lafuma C, d'Ortho MP 1999 Role of collagenase in mediating in vitro alveolar epithelial wound repair. J Cell Sci 112:243-252 
20. Pilcher BK, Sudbeck BD, Dumin JA, Welgus HG, Parks WC 1998 Collagenase-1 and collagen in epidermal repair. Arch Dermatol Res 290:S37-46

21. Vaalamo M, Leivo T, Saarialho-Kere U 1999 Differential expression of tissue inhibitors of metalloproteinases (TIMP-1, -2, -3, and -4) in normal and aberrant wound healing. Hum Pathol 30:795-802

22. Howard EW, Bullen EC, Banda MJ 1991 Preferential inhibition of 72- and 92-kDa gelatinases by tissue inhibitor of metalloproteinases-2. J Biol Chem 266:13070-13075

23. Kossakowska AE, Edwards DR, Lee SS, Urbanski LS, Stabbler AL, Zhang CL, Phillips BW, Zhang Y, Urbanski SJ 1998 Altered balance between matrix metalloproteinases and their inhibitors in experimental biliary fibrosis. Am J Pathol 153:1895-1902

24. Milani S, Herbst H, Schuppan D, Grappone C, Pellegrini G, Pinzani M, Casini A, Calabro A, Ciancio G, Stefanini F, et al 1994 Differential expression of matrixmetalloproteinase-1 and -2 genes in normal and fibrotic human liver. Am J Pathol 144:528-537

25. Selman M, Montano M, Ramos C, Chapela R 1986 Concentration, biosynthesis and degradation of collagen in idiopathic pulmonary fibrosis. Thorax 41:355-359

26. Hayashi T, Stetler-Stevenson WG, Fleming MV, Fishback N, Koss MN, Liotta LA, Ferrans VJ, Travis WD 1996 Immunohistochemical study of metalloproteinases and their tissue inhibitors in the lungs of patients with diffuse alveolar damage and idiopathic pulmonary fibrosis. Am J Pathol 149:1241-1256

27. Fukuda Y, Ishizaki M, Kudoh S, Kitaichi M, Yamanaka N 1998 Localization of matrix metalloproteinases-1, -2 , and -9 and tissue inhibitor of metalloproteinase- 2 in interstitial lung diseases. Lab Invest 78:687-698

28. Giedion A, Haefliger H, Dangel P 1973 Acute pulmonary X-ray changes in hyaline membrane disease treated with artificial ventilation and positive end-expiratory pressure (PEP). Pediatr Radiol 1:145-152

29. Bancalari E, Abdenour GE, Feller R, Gannon J 1979 Bronchopulmonary dysplasia: clinical presentation. J Pediatr 95:819-823

30. Laurent GJ 1987 Dynamic state of collagen: pathways of collagen degradation in vivo and their possible role in regulation of collagen mass. Am J Physiol 252:C1-9

31. Davidson JM 1990 Biochemistry and turnover of lung interstitium. Eur Respir J 3:1048-1063

32. Adamson IY, Bowden DH 1974 The type 2 cell as progenitor of alveolar epithelial regeneration. A cytodynamic study in mice after exposure to oxygen. Lab Invest 30:35-42

33. Adamson IYR, Bowden DH 1975 Derivation of type-1 epithelium from type-2 cells in the developing rat lung. Lab Invest 32:737-745
34. Kim HJ, Henke CA, Savik SK, Ingbar DH 1997 Integrin mediation of alveolar epithelial cell migration on fibronectin and type I collagen. Am J Physiol 273:L134-141

35. Pilcher BK, Dumin JA, Sudbeck BD, Krane SM, Welgus HG, Parks WC 1997 The activity of collagenase- 1 is required for keratinocyte migration on a type I collagen matrix. J Cell Biol 137:1445-1457

36. Burri PH 1997 Structural aspects of prenatal and postnatal development and growth of the lung. In: McDonald JA (ed) Lung Biology in Health and Disease. Marcel Dekker, New York, Basel, pp 1-35

37. Toti P, Buonocore G, Tanganelli P, Catella AM, Palmeri ML, Vatti R, Seemayer TA 1997 Bronchopulmonary dysplasia of the premature baby: an immunohistochemical study. Pediatr Pulmonol 24:22-28

38. Crouch EC, Mecham RP, Davila RM, Noguchi A 1997 Collagens and elastic fiber proteins in lung development. In: McDonald JA (ed) Lung Biology in Health and Disease. Marcel Dekker, New York, Basel, pp 327-364

39. Rolland G, Xu J, Tanswell AK, Post M 1998 Ontogeny of extracellular matrix gene expression by rat lung cells at late fetal gestation. Biol Neonate 73:112-120

40. Bonikos DS, Bensch KG, Northway Jr WH, Edwards DK 1976 Bronchopulmonary dysplasia: the pulmonary pathologic sequel of necrotizing bronchiolitis and pulmonary fibrosis. Hum Pathol 7:643-666

41. Stocker JT 1986 Pathologic features of long-standing "healed" bronchopulmonary dysplasia: a study of 28 3- to 40-month-old infants. Hum Pathol 17:943-961

42. Cherukupalli K, Larson JE, Rotschild A, Thurlbeck WM 1996 Biochemical, clinical, and morphologic studies on lungs of infants with bronchopulmonary dysplasia. Pediatr Pulmonol 22:215-229

43. Bateman ED, Turner-Warwick M, Adelmann-Grill BC 1981 Immunohistochemical study of collagen types in human foetal lung and fibrotic lung disease. Thorax 36:645-653

44. McAnulty RJ, Laurent GJ 1995 A Pathogenesis of lung fibrosis and potential new therapeutic strategies. Exp Nephrol 3:96-107

45. Pardo A, Selman M, Ramirez R, Ramos C, Montano M, Stricklin G, Raghu G 1992 Production of collagenase and tissue inhibitor of metalloproteinases by fibroblasts derived from normal and fibrotic human lungs. Chest 102:1085-1089

46. Edwards DR, Murphy G, Reynolds JJ, Whitham SE, Docherty AJ, Angel P, Heath JK 1987 Transforming growth factor beta modulates the expression of collagenase and metalloproteinase inhibitor. EMBO J 6:1899-1904 